\title{
THE INTERNAL BUNCH COORDINATE MONITOR (IBCK)
}

\author{
S.P. Yamin
}

November 4,1988

\section{DISCLAIMER}

This report was prepared as an account of work sponsored by an agency of the United States Government. Neither the United States Government nor any agency thereof, nor any of their employees, makes any warranty, express or implied, or assumes any legal liability or responsibility for the accuracy, completeness, or usefulness of any information, apparatus, product, or process disclosed, or represents that its use would not infringe privately owned rights. Reference herein to any specific commercial product, process, or servicc by trade name, trademark, manufacturer. or otherwise does not necessarily constitute or imply its endorsement, receinmendation, or favoring by the United States Government or any agency thereof. The views and opinions of authors expressed herein do not necessarily state or reflect those of the United States Government or any agency thereor.

\section{INFORMAL REPORT}

\section{ALTERNATING GRADIENT SYNCHROTRON DEPARTMENT}

\author{
BROOKHAVEN NATIONAL LABORATORY \\ Associated Universities, Inc. \\ Upton, Iong Island, New York 11973 \\ Under contract No. DE-AC02-76CH00016 with the
UNITED STATES DEPARTMENT OF ENERGY
}

\section{MASTER}


BNL- -42090

TI89 006106

THE INTERNAL BUNCH COORDINATE MONITOR (IBCM)

S.P. Yamin

November 4,1988

INFORMAL REPORT

ALTERNATING GRADIENT SYNCHROTRON DEPARTMENT

BROOKHAVEN NATIONAL LABORATORY

Associated Universities, Inc.

Upton, Long Island, New York 11973 


\section{INTRODUCTION}

An instrument has been developed and installed at the AGS for recording the transverse motion of each rf bunch. It can pe operated from any node of the Apollo control system; A preliminary version of this report has appeared elsewhere. 1 Appendix $A$ is an instruction manual.

Two digitizers, running off the same $100 \mathrm{MHz}$ clock, sampled the output of either a horizontal or vertical pick-up electrode (PUE) pair. The coordinate of each rf bunch was calculated each time it passed the PUEs during a 320 microsecond interval. Thus, the motion of each bunch could be followed during this interval. subsequent analysis computed the Fourier transform of this motion.

Bunch motion has been studied at several times during the AGS cycle: the betatron oscillations induced by the tune meter's vertical kick have been seen, and their Fourier analysis gives results consistent with the tune meter; at transition, the effect of the radial kick on each bunch has been observed; coupled-bunch oscillations have been studied; and j.nstabilities produced by high intensities have been observed.

\section{APPARATUS}

The IBCM is located in the $\mathrm{K}-18$ House and is connected by fast cables to the PUEs in the $\mathrm{K}-8$ straight section. A logical plan of the apparatus appears as Figure 1 .

A pair of LeCroy $8818100 \mathrm{MHz}$ CAMAC transient recorders is interfaced to an IBM-PC/XT computer which, in turn, is interfaced to the AGS Apollo control system via the RELHAY data link. A program in the PC converts the bunch digitizations into coordinates, passing these on to the Apollo, where Fourier analysis is performed.

Signals from a vertical or horizontal PUE pair are fed through attenuators, where small gain differences are removed, and to the Lecroy 8818 digitizers. The Apollo system starts the sampling, which continues for 320 microseconds after a "stop" signal is received. (At present, this is a standard AGS $15 \mathrm{~V}$ signal transmitted by dedicated cable from the control room to the IBCM.) The last 320 microseconds of data are then transferred to the IBM-PC for preliminary processing. Here, pulses

IP. Yamin, "IBCM: Internal Bunch Coordinate Monitor," Proceedings 1987 IEEE Particle Accelerator Conference, Accelerator Engineering \& Technol., IEEE Cat. No. 87CH2387-9, Vol 1, 603 (1987). 
are identified and the 5-7 samples representing the 50-70 ns pulse from each PUE are summed to form inner/outer or upper/lower signals. The position of each bunch is then determined as $\mathrm{X}=($ inner-outer $) /$ (inner+outer) or $\mathrm{Y}=$ (upper-lower $) /($ upper+lower $)$.

These data, representing the horizontal or vertical coordinate for each of the 12 AGS bunches as they passed the K-8 PUE during the 320 microsecond sampling interval, are transmitted via RELWAY to the Apollo.

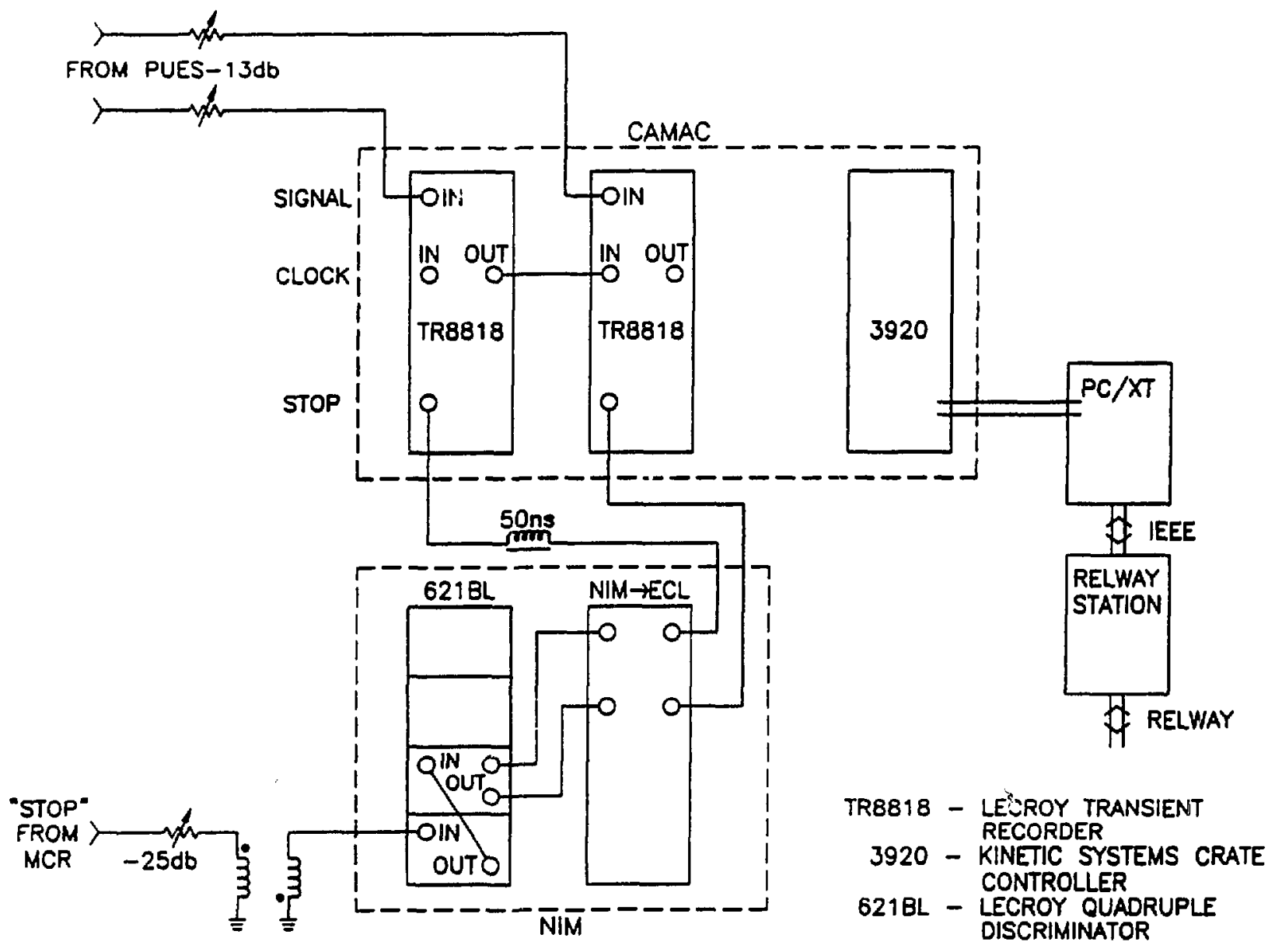

Figure i. 
At the Apollo, the transmitted data are written to a disk file for subsequent analysis. The present analysis program reads this file and produces twelve (one for each bunch) sets of output which display: a plot of the coordinate of each bunch as it passed the PUE on successive turns; the real and imaginary parts of the Fourier transform of the first 64 points in this plot; and a plot of the power spectrum of the Fourier transform.

All of the Apollo and IBM-PC codes likely to be of interest to the physics- or operations-oriented user were written in FORTRAN by the author, and can readily be modified to suit evolving needs. (The part written by "professionals" concerns communication on the CAMAC link between the digitizers and IBM-PC, the IEEE link between the IBM-PC and the RELWAY station, and the control of the Apollo/RELWAY interface.) More information about these programs, including listings, is available from the author.

III. RESULTS

In order to reassure ourselves that we were looking at real effects, we first tested the monitor on a known phenomenon: large-amplitude betatron oscillations produced by the tune meter's vertical kicker. Figures $2 \mathrm{a}-\mathrm{c}$ show data for a typical bunch taken during a 320 microsecond window beginning shortly after a kick was applied. 
(a) BUNCH 2

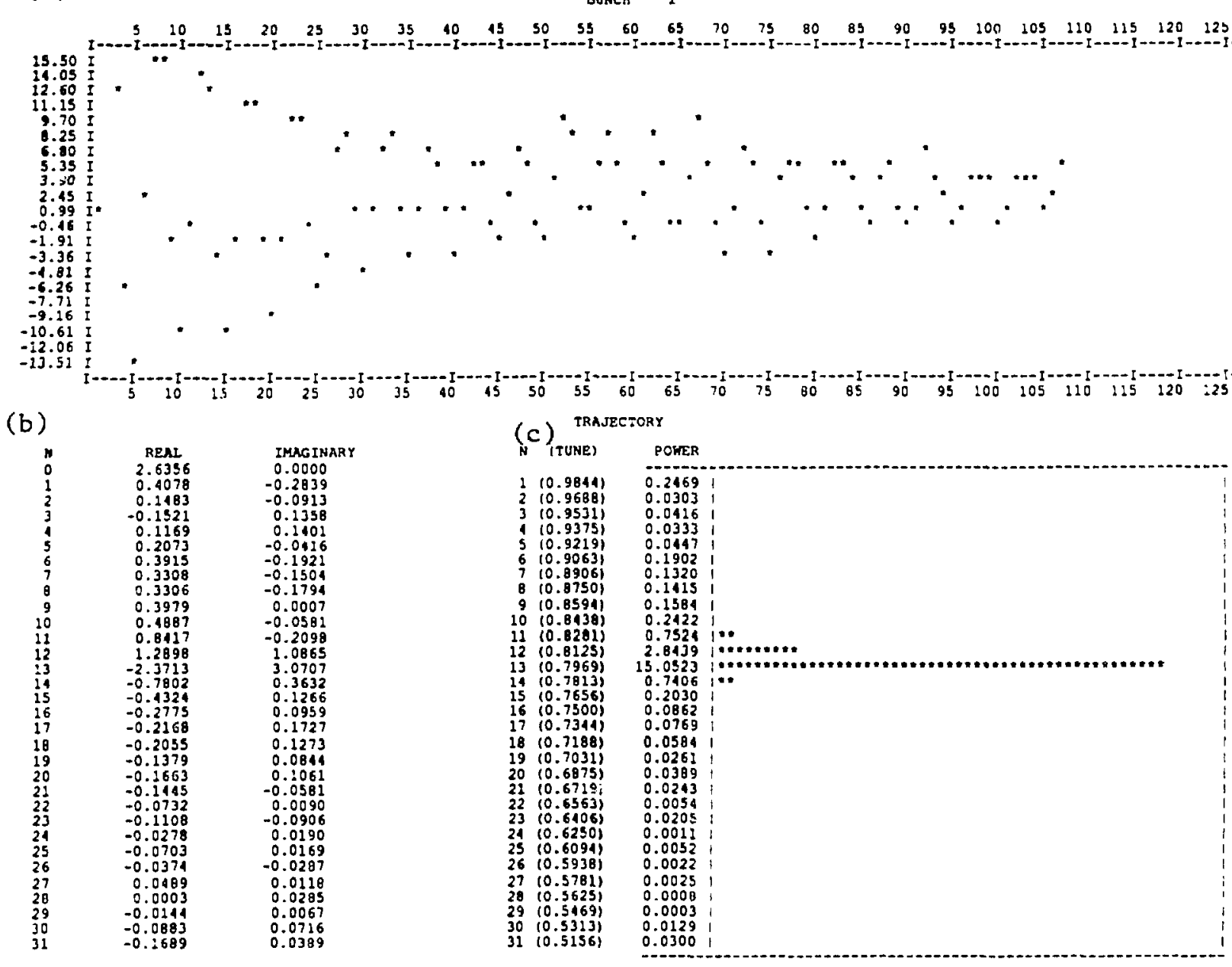

FOURIER TRANSFORM OF FIRST 64 POINTS IN TRAJECTORY

POWER SPECTRUM OF FOURIER TRANSFORM

Figure 2.

The decaying oscillation is readily apparent in Fig. 2a, where the ordinate represents amplitude as a percentage of PUE spacing and the abscissa the turn number. The period of the oscillations is about 5 turns and the decay time about 85 turns. From this we can immediately conclude that the fractional part of the tune is about $1-1 / 5=0.8$ and the tune spread about $1 / 85=0.012$. Figure $2 \mathrm{~b}$ is the Fourier transform of the first 64 points in Fig. $2 \mathrm{a}$. since the Fourier transform is computed over an interval of 64 turns, the index $\mathrm{N}=0$ represents the dc component of the signal, $\mathrm{N}=1$ the frequency corresponding to a period of 64 turns, $N=2$ the frequency corresponding to a period of 32 turns, etc. These data are more readily comprehensible as a power spectrum (the sum of the squares of the real and imaginary parts of the respective amplitudes), which is shown in Fig 2c., and where we also show the fractional part of the tune in parentheses. The peak is striking, and its position agrees with both the tune meter measurement and the approxination given above. 
Figures $3 a-c$ show similar data, but the position of the timing window is such that the vertical kick is visible.

(a)

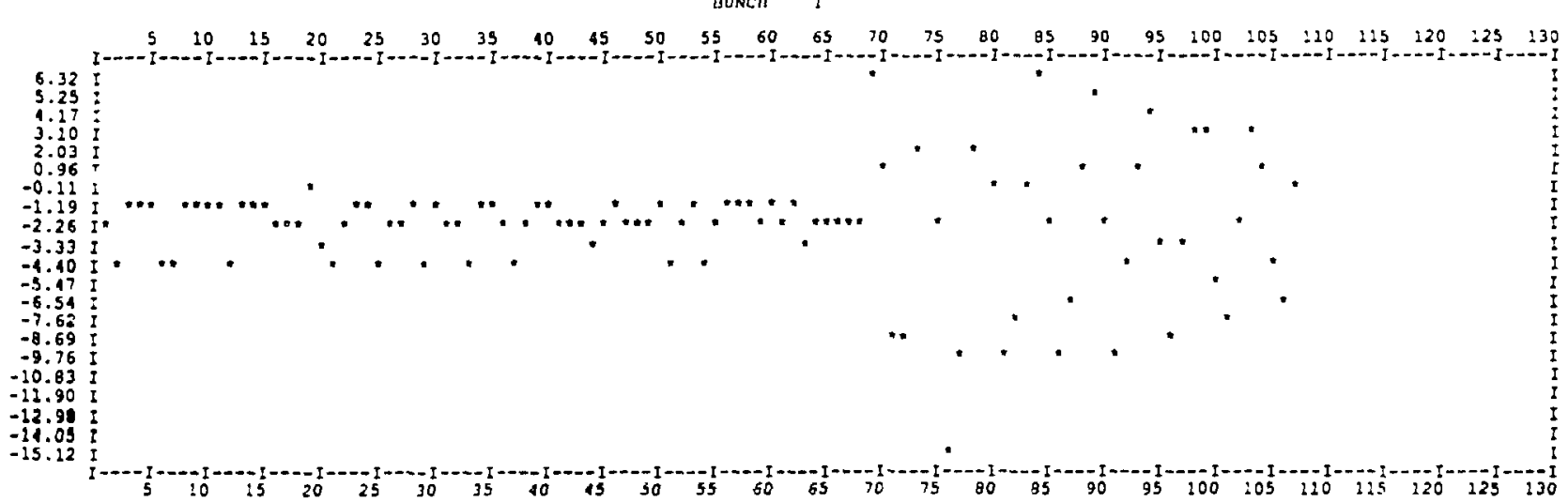

(b)

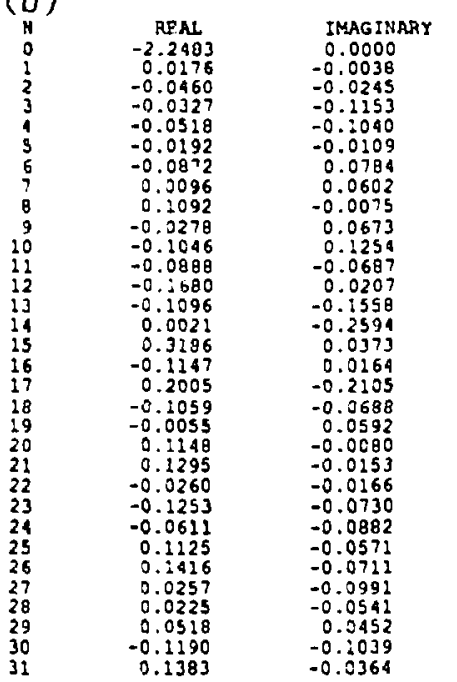

(c) trajecroRy

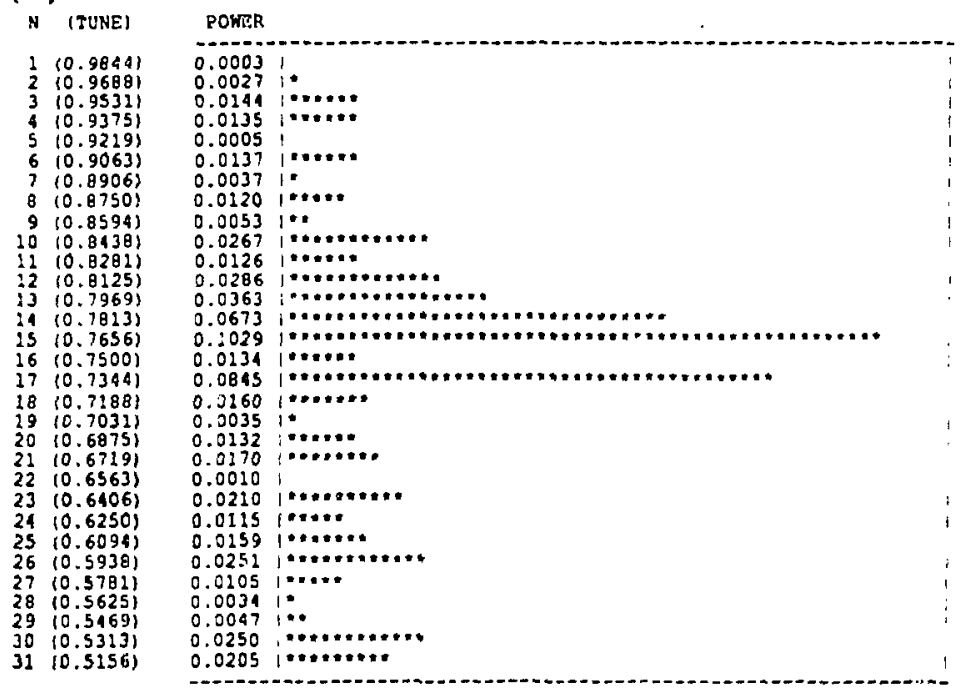

POWER SPECTRUM OE GOUR:ER TRANSFORM

\section{Figure 3.}

since the Fourier transfrim is computed only for the first 64 turns, where no large betatron oscillations are present, we cannot expect a sharp peak. Nevertheless, the ture can be identified as the broad peak centered at about 0.8 in Fig. $3 \mathrm{C}$. 
Next, we studied the transition region, and representative data may be found in Figs. $4 a-c$.

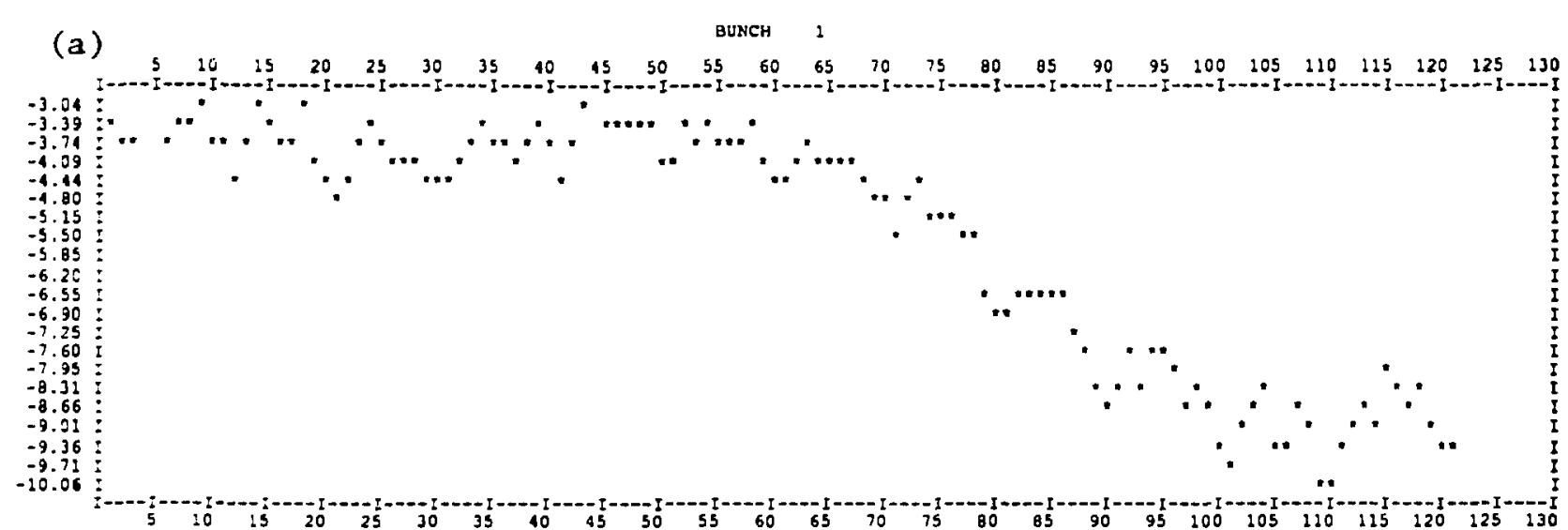

(b)

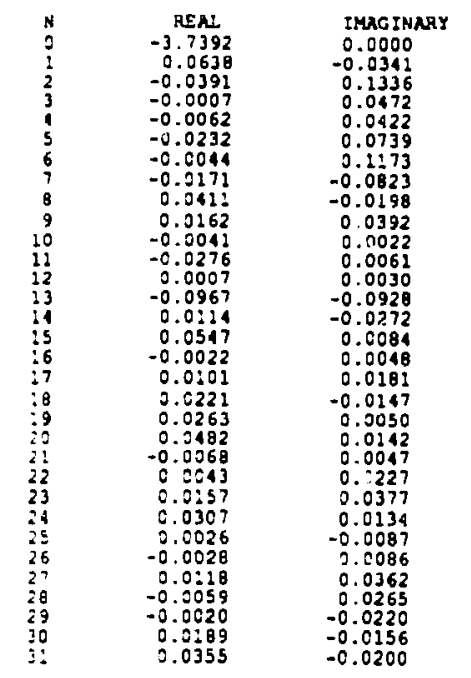

FCURIER TRANSFORM CF FIAST 64 POIHTS IN TAMJECTORY (c)

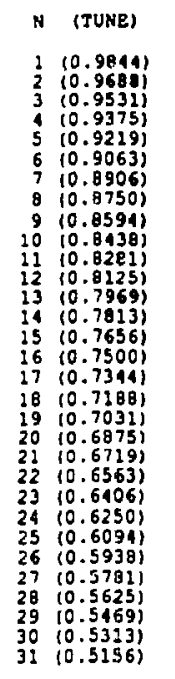
TRAJECTORY

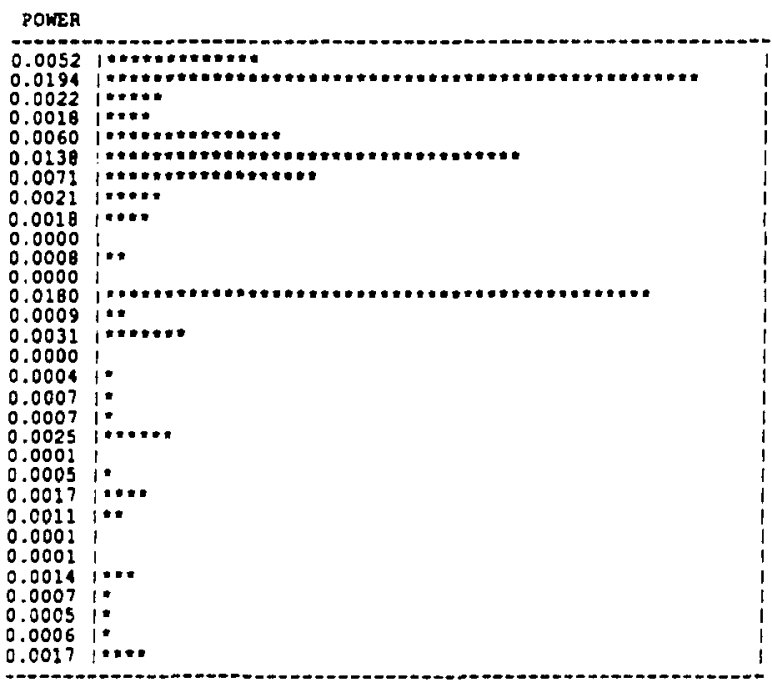

POWER SPECTRUM OF FOURIER TRANSFORM

Figure 4.

The notable feature in Fig. $4 \mathrm{a}$ is the shift in orbit as transition is crossed, moving inward by about $6 \%$ of the 4 " horizontal PUE spacing--about $0.25^{\prime \prime}$. The peaks in the power spectrum, shown in Fig $4 \mathrm{c}$ and centered in channels 2,6 , and 13, are probably oscillations induced by the (perturbing) orbit bump used to speed up passage through transition. 
Coupled-bunch oscillations ${ }^{2}$ have been observed. Here, the wakefield of each bunch perturbs following bunches. This effect is caused by sharp peaks in the accelerator impedance--resonances with high enough Q-values to sustain the wakefield for the $220 \mathrm{~ns}$ interval between bunches. For $M$ circulating bunches, $M$ coupled modes are possible, with a phase shift of $2 \pi \mathrm{n} / \mathrm{M}$ between bunches for mode $n$.

Each bunch can also oscillate transversely in several modes, which are usually denoted by the integer $\mathrm{m}$. For example, $\mathrm{m}=0$ corresponds to rigid motion of the bunch as a whole and $\mathrm{m}=1$ to "head-tail" oscillations about the center of the bunch. In the case of zero chromaticity, $m=0$ oscillations appear at the betatron frequency. Finite chromaticity produces a frequency shift.

Because the tune depends on momentum, the betatron frequency varies cyclically as particles undergo synchrotron oscillations. This has the effect of modulating the betatron frequency signal and shifting its frequency spectrum by an amount $\xi / \eta$, where $\xi$ is the chromaticity and $\eta=1 / \gamma^{2}-1 / \gamma^{2}$ is the dispersion in revolution frequency. However, since the algorithm used to determine the bunch position (which is described in section II) integrates over the entire bunch length and the frequency response of the PUE electronics is limited, the IBCM as presently constituted is not sensitive to the effects of chromaticity or modes other than $\mathrm{m}=0$.

Coupled bunch oscillations can be used to study the AGS impedance. The presence of these oscillations at a particular point in the AGS cycle indicates a peak in the impedance at the corresponding revolution frequency and mode. Figure 5 is an example of vertical coupled-bunch oscillations. Here, only trajectories for the first four bunches are shown, together with the Fourier analysis for Bunch 4. Oscillations at the same frequency are obvious, and the systematic bunch-to-bunch phase shift is emphasized by the diagonal line.

2F. Sacherer, "Bunched Beams," Theoretical Aspects of the Behavior of Beams in Accelerators and Storage Rings, CERN (Ettore Majorana, 198, (1976) 


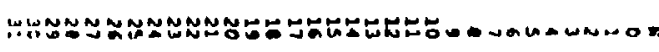

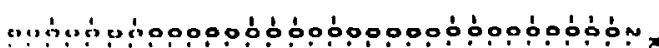
กำ

dooódooopopobophodódopopopobopon \%80 U幺.

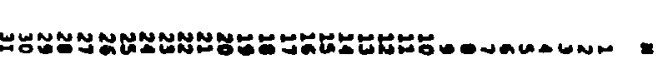

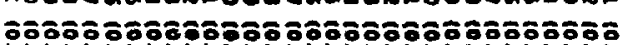

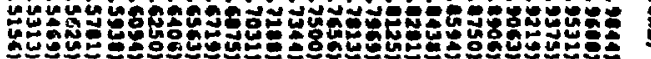
\%000009000000000000000909040000

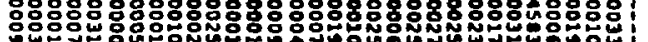

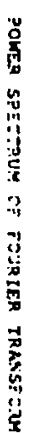

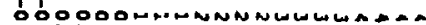

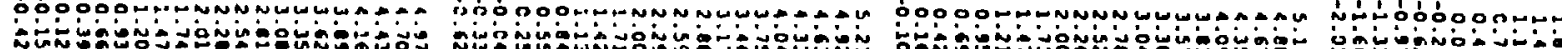
F...umgan

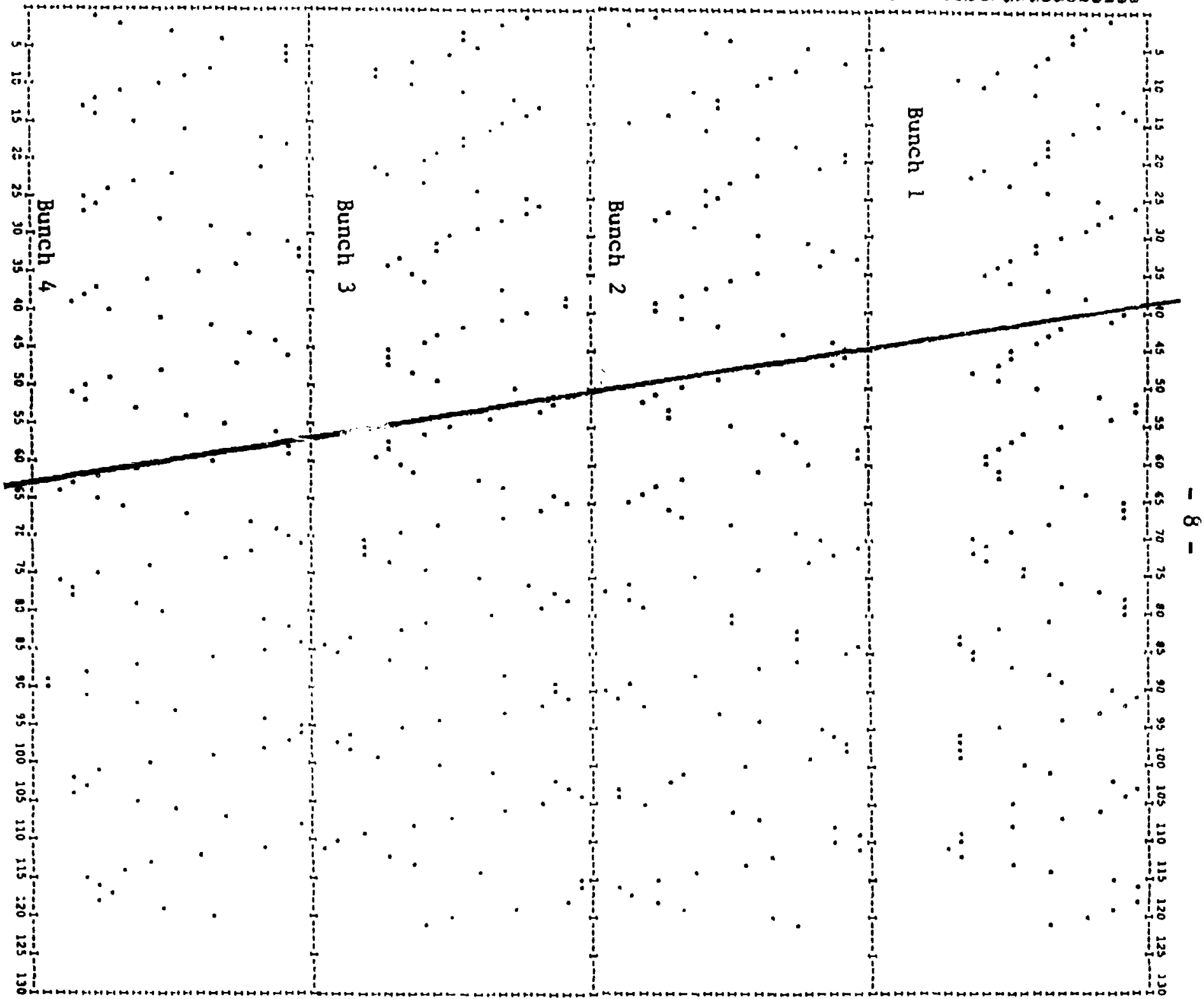


The phase of any spectral component is the arctangent of the ratio of its imaginary-to-real parts, and the phase shift between bunches is the difference between the two phase angles. Table I shows the Fourier transforms for Bunches $1-3$ plotted in Fig. 5. The principal line in the spectrum occurs at $N=5$, so for the first bunch the angle is $15.5^{\circ}$ and for the second $171.4^{\circ}$. The phase shift is therefore $155.9^{\circ}$. Since there are twelve bunches in the AGS this means we are looking at the mode which corresponds to $n=5$. The data were taken $320 \mathrm{~ms}$ after $t_{0}$, so we can infer a peak in the transverse impedance at the frequency corresponding to this AGS energy and mode, $23.93 \mathrm{MHz}$.

Table I

Bunch 1

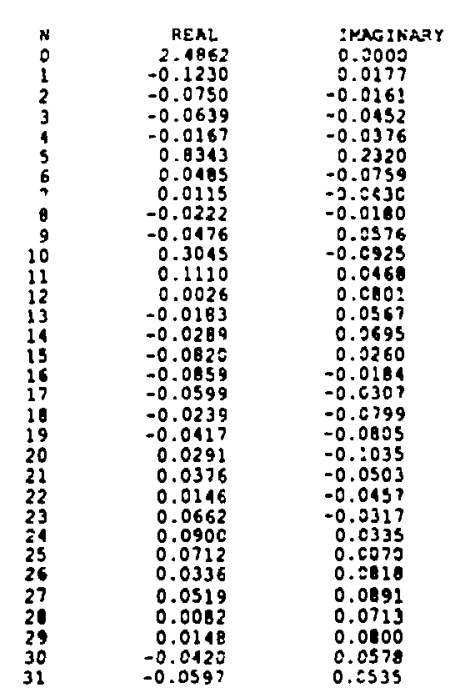

Bunch 2

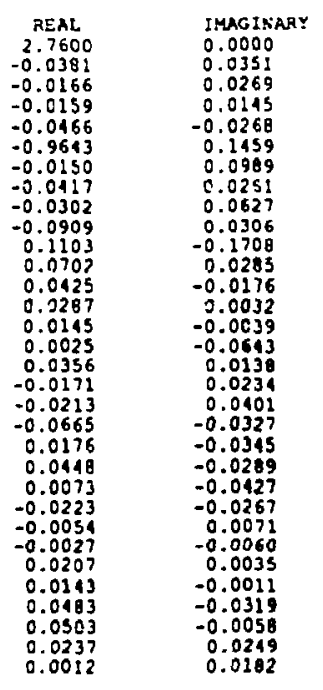

Bunch 3

$\begin{array}{lcc}N & \text { IEAL } & \text { IMAGINARY } \\ 0 & 2.5150 & 0.0000 \\ 1 & -0.0311 & 0.0202 \\ 2 & 0.0163 & 0.0193 \\ 3 & 0.0045 & -0.0031 \\ 1 & 0.0631 & 0.0735 \\ 5 & 0.0414 & 0.0265 \\ 6 & -0.0707 & -0.0695 \\ 7 & -0.0579 & -0.0187 \\ 8 & -0.0602 & -0.0003 \\ 9 & -0.0832 & 0.0213 \\ 10 & 0.0913 & -0.2379 \\ 11 & 0.0218 & -0.0293 \\ 12 & 0.0233 & -0.0286 \\ 13 & -0.0035 & -0.0208 \\ 14 & 0.0398 & 0.0016 \\ 15 & 0.0126 & -0.0123 \\ 16 & -0.0175 & -0.0066 \\ 17 & 0.0270 & 0.0094 \\ 18 & 0.0012 & -0.0029 \\ 19 & 0.0100 & 0.0042 \\ 20 & -0.0213 & -0.0263 \\ 21 & 0.0344 & 0.0317 \\ 22 & 0.0017 & -0.0237 \\ 23 & -0.0031 & 0.0036 \\ 24 & -0.0032 & -0.0019 \\ 25 & -0.0241 & 0.0136 \\ 26 & 0.0076 & -0.0173 \\ 27 & 0.0061 & -0.0137 \\ 28 & -0.0171 & -0.0292 \\ 29 & -0.0139 & -0.0161 \\ 30 & 0.0092 & -0.0247 \\ 31 & -0.0177 & 0.0075 \\ & & \end{array}$


Finally, Fig. 6 shows data taken during an as yet not understood instability. Although the motion appears chaotic, the Fourier spectrum shows striking regularities. Perhaps further study will prove illuminating.
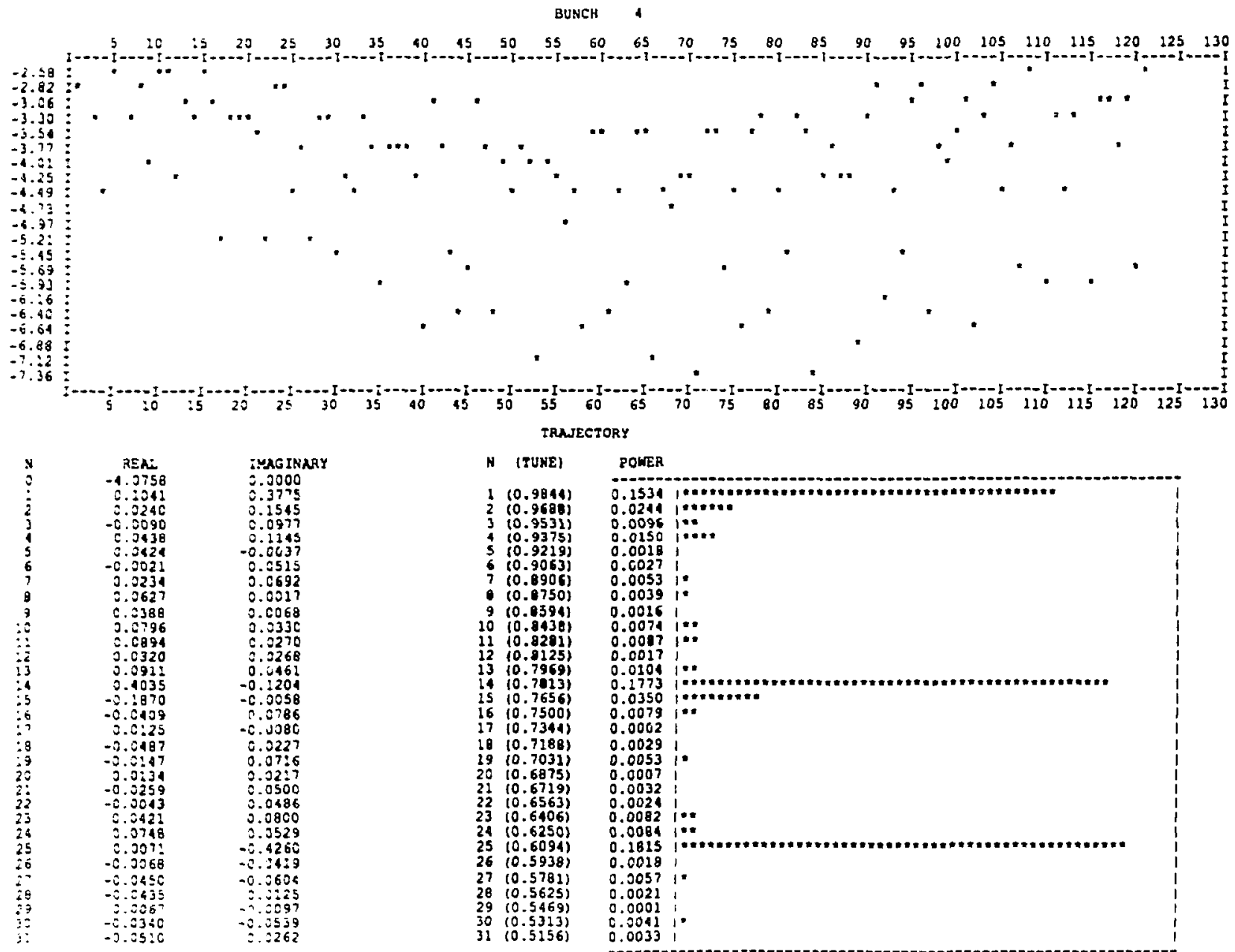

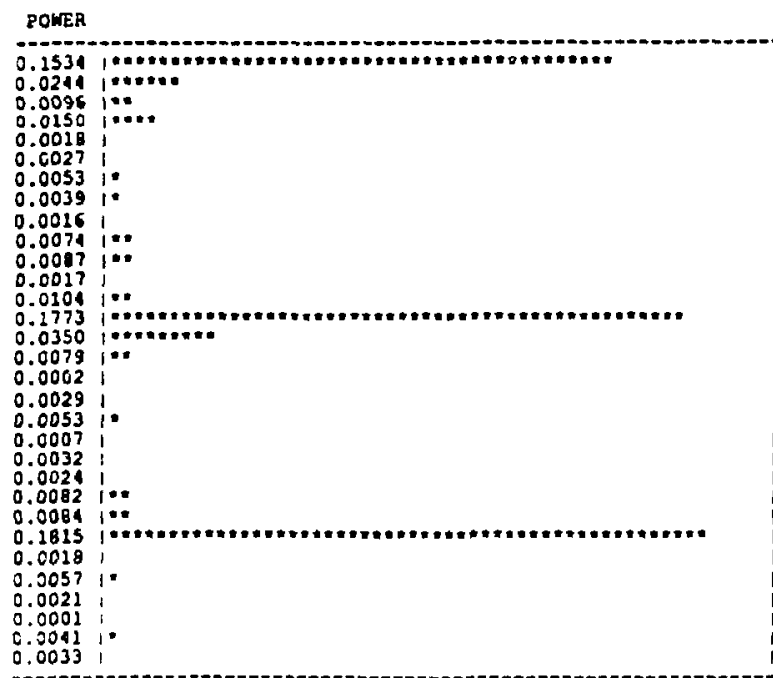

POWER SPECTRUM OF FOURIEA TRANSFORM 
IV. CONCLUSION

I. believe that the IBCM has proved itself a useful aid in better understanding AGS behavior. Since it is now integrated into the Apollo control system, it is hoped that it will be helpful to others. Increasing the frequency response of the PUE system to at ieast $200 \mathrm{MHz}$ and replacing the $100 \mathrm{MHz}$ transient recorders with state-of-the-art $1 \mathrm{GHz}$ units would enable the IBCM to detect the effects of finite chromaticity on coupled-bunch oscillations.

\section{ACKNOWLEDGMENTS}

It is a pleasure to thank some of the people who helped me:

Sue Kennell wrote the IBM-PC code which connects iny FORTRAN to the Apollo/RELWAY world and Tom Clifford wrote the code which reconnects to FORTRAN on the Apollo end. Bnth of these people endured my often uninformed pestering, and I am grateful. Elliot Auerbach was a living reference manual for the Apollo system.

Discussions with Gene Raka elucidated some of the subtle (and not so subtle!) points of machine theory of which I was ignorant. Willem van Asselt bugged me about the test with the tune meter until we did it. Ed Gill made sure I got the signals I needed, while John Post and Carl Eld strung many of the cables which conduct these signals to where they are wanted. 


\section{APPENDIX A: RUNNING THE IBCY}

Running the IBCM involves getting the electronics in the K-18 House going, starting the IBM-PC there, establishing a timing "stop" signal, and connecting to an Apollo ncde.

\section{In the $\mathrm{K}-18$ House}

Please refer to Fig. 1 for a logical plan of the apparatus.

1. Turn on the power for the CAMAC crate, the NIM crate, and the IBM-PC. Make sure that all voltages come up.

2. Set the CAMAC crate controller to "off Iine" and initialize the dataway. Return the controller to "on line."

3. The IBM-PC should display the prompt "C\BUNCHMON>." Type "BUNCH2 [carriage return]," the name of the resident program.

4. The computer screen should display:

INITIAL STATUS $=010000010000$

WAIT

GOGO

This means that the IEEE interface to RELWAY is alive and that the system is awaiting commands from an Apollo node via RELWAY.

\section{In the AGS Control Room}

Arrange to have a standard $15 \mathrm{~V}$ "stop" signal hooked up to the dedicated line running to the $\mathrm{K}-18$ House. (You will probably get this from a predet.) Remember that the interval being digitized begins at "stop" and lasts for 320 microseconds. 


\section{At An Apol 10 Node}

Log on. From the area YAMIN/HOME/USER get the executable files READBUNCHMON anc TURNS3.

To begin digitizing, type:

$$
\text { READBUNCHMON > filename [carriage return], }
$$

where the "filename" is the name of the Apollo file in which the results of the digitization are to be stored. Digitizing begins and continues until the IBCM receives a "stop" signal. It will take about a liinute for the computer in the $\mathrm{K}-18$ House to complete the preliminary analysis and to transmit the data back for storage in "filename." (The IBCM is now ready for collecting more data. You may proceed again as above or continue with the analysis.)

$$
\begin{aligned}
& \text { To continue the analysis, type: } \\
& \text { TURN53 < filename [carriage return] }
\end{aligned}
$$

This applies the Fourier analysis to the data in "filename," and produces the plots described in section II of this report. Using standard Apollo data manipulation techniques, you can copy all or part of the final output file to a laser printer. 